\title{
Sistem Pendukung Keputusan Penentuan Lokasi Industri Berbasis Spasial Menggunakan Metode MOORA
}

\author{
Agusta Praba Ristadi Pinem ${ }^{1 *}$, Henny Indriyawati ${ }^{2}$, Basworo Ardi Pramono ${ }^{3}$ \\ Jurusan Teknologi Informasi, Fakultas Teknologi Informasi dan Komunikasi \\ Universitas Semarang, Semarang \\ Jln. Soekarno Hatta, Tlogosari Semarang, 50196 \\ email: ${ }^{1}$ agusta.pinem@usm.ac.id, ${ }^{2}$ henny@usm.ac.id, ${ }^{3}$ basworo@usm.ac.id
}

\begin{abstract}
Abstrak
Seiring waktu dengan pesatnya perkembangan teknologi informasi, setiap organisasi akan selalu menghimpun data maupun informasi. Informasi yang terhimpun dijadikan sebagai dasar dalam pengambilan keputusan. Namun tidak semua informasi dapat langsung digunakan untuk proses pengambilan keputusan. Perlu metode serta pembobotan didalam proses mendapatkan informasi. Salah satu metode yang dapat digunakan dalam mendukung proses pengambilan keputusan adalah Multi-Objective Optimization on the basis of Ratio Analysis (MOORA). MOORA termasuk dalam Multi Criteria Decision Making yang memungkinkan untuk memberikan informasi pilihan terbaik dari beberapa pilihan terhadap kriteria yang digunakan. Penelitian ini menggunakan metode MOORA sebagai penentuan lokasi industri strategis dengan mengkombinasikan dengan data spasial. Dalam menentukan lokasi industry yang strategis, MOORA menggunakan beberapa kriteria serta bobot yang berbeda untuk setiap kriteria. Metode MOORA diharapkan dapat menghasilkan informasi yang tepat terkait penentuan lokasi industry strategis dengan mencari korelasi hasil metode dengan data lokasi industry di Kota Semarang. Hasil yang diperoleh dari penelitian ini adalah terbentuknya model sistem pendukung keputusan penentuan lokasi industri menggunakan metode MOORA berbasis data spasial. Nilai korelasi Spearman Rank yang dihasilkan adalah 0,9.
\end{abstract}

Kata kunci-SPK, MOORA, Lokasi Industri, Spearman Rank

\begin{abstract}
Information technology is developing rapidly and the effect is every single organization will always collect data and information. The information collected is used as a basis for decision making. But not all information can be directly used for the decision making process. Method and weighting are needed in the process of getting information. One method that can be used to support the decision making process is Multi-Objective Optimization on the basis of Ratio Analysis (MOORA). MOORA is included in the Multi Criteria Decision Making (MCDM) which makes it possible to provide the best choice of information from several choices by using criteria values. This research uses the MOORA method as determining strategic industrial locations by combining spatial data. In determining the strategic location of the industry, MOORA uses several criteria and different weights for each criteria. The MOORA with spatial data can be produce the right information related to the determination of strategic industry locations by finding the correlation between method results with industry location in Semarang city. The results obtained from this research are the formation of a decision support system modeling of industrial location determination using the MOORA method with spatial data. Correlation value generated by the Spearman Rank method is 0,9.
\end{abstract}

Keywords - DSS, MOORA, Industry Location, Spearman Rank 


\section{PENDAHULUAN}

Teknologi informasi berperan aktif dalam membantu pekerjaan manusia, khususnya dalam pertukaran data dan informasi. Pertukaran informasi memudahkan pengguna untuk mengambil keputusan yang tepat. Pengambilan keputusan akan sesuai harapan apabila didukung dengan data dan informasi yang lengkap. Informasi sendiri diperoleh dari proses didalam sistem yang terdiri dari algoritma yang memproses data.

Model metode pengambilan keputusan salah satunya adalah Multi Criteria Decision Making (MCDM). Metode (MCDM) digunakan di banyak bidang kegiatan manusia. Setiap alternatif dalam masalah pengambilan keputusan multikriteria dapat dijelaskan oleh satu set kriteria dan kriteria dapat bersifat kualitatif maupun kuantitatif [1]. Salah satu metode sistem pendukung keputusan (SPK) dengan model MCDM yaitu Multi-Objective Optimization on the basis of Ratio Analysis (MOORA) [2]. Metode MOORA melakukan perangkingan dengan membandingkan nilai setiap kriteria pada masing-masing alternative dengan melihat bobot masing-masing untuk memperoleh alternative yang ideal [3].

Metode SPK terutama MOORA telah banyak diimplementasikan di banyak bidang. MOORA diterapkan dalam menentukan pemilihan mesin otomatis pada proses manufacturing [4]. Selain itu metode MOORA telah diterapkan pada bidang manufacturing dan industri, yaitu penentuan prioritas ketersediaan mobil sebagai bentuk safety stock [3], penentuan supply chain supplier berdasarkan jumlah diskon dan tingkat resiko [5], penentuan supplier logistik pada agile manufacturing [6], pemilihan bahan material pada manufaktur [7], penentuan mesin pemotong baja [8], penentuan supplier mesin pengemasan [9] dan pemilihan pihak ketiga penyedia logistik pada industri plastik [1]. Selain itu MOORA juga digunkan untuk menentukan lokasi SPBU [10].

Metode MOORA dimulai dengan matriks keputusan yang menunjukkan kinerja berbagai alternatif sehubungan dengan berbagai kriteria. Kemudian matriks keputusan dinormalisasi sehingga menjadi dimensi bebas dan semua elemennya dapat dibandingkan. Dalam proses normalisai, kategori kriteria belum diperhatikan dalam perhitungan. Hasil normalisasi memiliki rentang 0-1 sehingga dapat dibandingkan satu dengan lainnya. Kemudian dalam menentukan rangking, nilai normalisasi dikalikan dengan bobot kriteria dan masing masing kriteria dikelompokan berdasarkan kategori kriteria.

\section{METODE PENELITIAN}

MOORA merupakan metode untuk menganalisa alternative berdasarkan keluaran dari total keseluruhan kriteria benefit dan kriteria cost [9]. Metode MOORA melakukan proses mengoptimalkan secara simultan dua atau lebih kriteria yang saling bertentangan (sasaran) dengan memaksimalkan kriteria benefit dan meminimalkan kriteria cost [7]. MOORA mempertimbangkan tujuan (kriteria) yang menguntungkan dan tidak bermanfaat untuk menentukan peringkat atau memilih satu atau lebih alternatif dari sekumpulan opsi yang tersedia [7]. MOORA menghitung kinerja keseluruhan dari setiap alternatif sebagai perbedaan antara jumlah kinerja normal dari atribut yang benefit dan yang cost [2]. Metode MOORA dimulai dengan matriks keputusan yang menunjukkan kinerja berbagai alternatif sehubungan dengan berbagai kriteria. Dalam proses normalisai, kategori kriteria belum diperhatikan dalam perhitungan. Hasil normalisasi memiliki rentang 0-1 sehingga dapat dibandingkan satu dengan lainnya. Kemudian dalam menentukan rangking, nilai normalisasi dikalikan dengan bobot kriteria dan masing masing kriteria dikelompokan berdasarkan kategori kriteria. Dalam melakukan perangkingan, metode MOORA memiliki beberapa langkah yaitu: 


$$
\begin{gathered}
\text { Pembentukan Decicion Making Matrix } \\
x=\left[\begin{array}{ccccc}
x_{01} & \cdots & x_{0 j} & \cdots & x_{0 n} \\
\vdots & \ddots & \vdots & \ddots & \vdots \\
x_{i j} & \cdots & x_{i j} & \cdots & x_{n j} \\
\vdots & \ddots & \vdots & \ddots & \vdots \\
x_{n 1} & \cdots & x_{m j} & \cdots & x_{m n}
\end{array}\right] i=m, 0 ; j \\
\\
=1, n
\end{gathered}
$$

Dimana $\mathrm{m}=$ jumlah alternative, $\mathrm{n}=$ jumlah kriteria

$\mathrm{xij}=$ nilai performa dari alternative $\mathrm{i}$ terhadap kriteria $\mathrm{j}$

$\mathrm{x} 0 \mathrm{j}=$ nilai optimum dari kriteria $\mathrm{j}$

Penormalisasian Decision Making Matrix untuk semua kriteria

$$
X_{i j}^{*}-X_{i j} / \sqrt{\left[\sum_{i=1}^{m} X_{i j}^{2}\right]}
$$

Matrik keputusan ternormalisasi untuk semua kriteria

$$
\bar{x}=\left[\begin{array}{ccccc}
\bar{x}_{01} & \cdots & \bar{x}_{0 j} & \cdots & \bar{x}_{0 n} \\
\vdots & \ddots & \vdots & \ddots & \vdots \\
\bar{x}_{i j} & \cdots & \bar{x}_{i j} & \cdots & \bar{x}_{n j} \\
\vdots & \ddots & \vdots & \ddots & \vdots \\
\bar{x}_{n 1} & \cdots & \bar{x}_{m j} & \cdots & \bar{x}_{m n}
\end{array}\right] i=\bar{m}, 0 ; j
$$

Menentukan bobot matriks yang sudah dinormalisasi

$$
\sum_{j=1}^{n} w_{j}=1
$$

Menentukan nilai maximax dan minmax

$$
Y_{i}=\sum_{j=1}^{g} w_{j} x_{i j}^{*}-\sum_{j=g+1}^{n} w_{j} w_{i j}^{*}
$$

Alternatif dengan nilai $Y i$ terbesar menghasilkan alternative terbaik berdasarkan urutan sehingga menghasilkan rangking.

Pada penelitian ini menggunakan data sekunder yang diperoleh dari BAKOSURTANAL (Badan Koordinasi Survei dan Pemetaan Nasional) dan Open Data Kota Semarang sebagai data alternatif dan kriteria. Data lokasi kawasan industri atau kriteria menggunakan data spasial. Data Spasial merupakan data representasi lokasi geografis dimuka bumi yang sering digunakan dalam bidang sistem informasi geografis (SIG) [11] [12]. Data spasial yang diperoleh dari Query Spatial menjadi nilai kriteria pada setiap alternative yang kemudian diproses dengan metode MOORA. Data spatial yang digunakan meliputi tabel 1 dibawah ini berdasarkan kriteria pada kasus penentuan lokasi industry [13].

Tabel 1. Data Spatial

\begin{tabular}{|l|l|l|l|}
\hline No & Kriteria & Tipe & Keterangan \\
\hline 1 & Pusat Kota & Point & Titik pusat kota terdekat \\
\hline 2 & Pemukiman & Polygon & Lahan peruntukan pemukiman \\
\hline 3 & Area Lahan & Polygon & Jenis lahan peruntukan \\
\hline 4 & Kemiringan Lereng & Polygon & Kemiringan lahan \\
\hline 5 & Jenis Tanah & Polygon & Jenis tanah \\
\hline 6 & Sungai & Line & Garis sungai di Pulau Jawa \\
\hline 7 & Jalan & Line & Jalan berdasarkan tipe jalan \\
\hline
\end{tabular}

Pinem, et, al [Sistem Pendukung Keputusan Penentuan Lokasi Industri Berbasis Spasial Menggunakan Metode MOORA] 
Data spatial yang digunakan terdiri dari koordinat $\mathrm{x}$ dan $\mathrm{y}$. Untuk jenis point maka hanya terdiri dari satu $\mathrm{x}$ dan $\mathrm{y}$. Sedangkan untuk tipe polygon dan line terdiri dari kumpulan koordinat yang membentuk garis dan area.

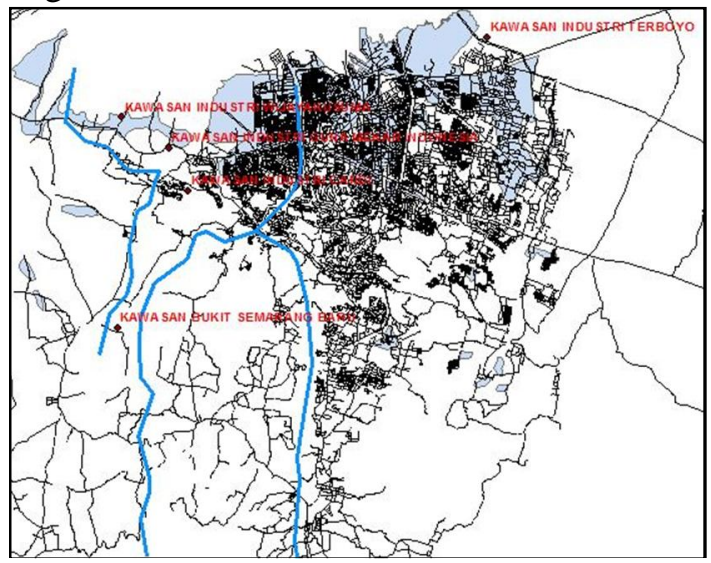

Gambar 1. Peta Jaringan Jalan, Sungai dan Pusat Kota

Gambar 1 adalah peta digital untuk data garis jalan, garis sungai dan titik pusat kota yang kemudian dilakukan import ke database dan tersimpan dalam bentuk koordinat yang selanjutnya dilakukan query spatial.

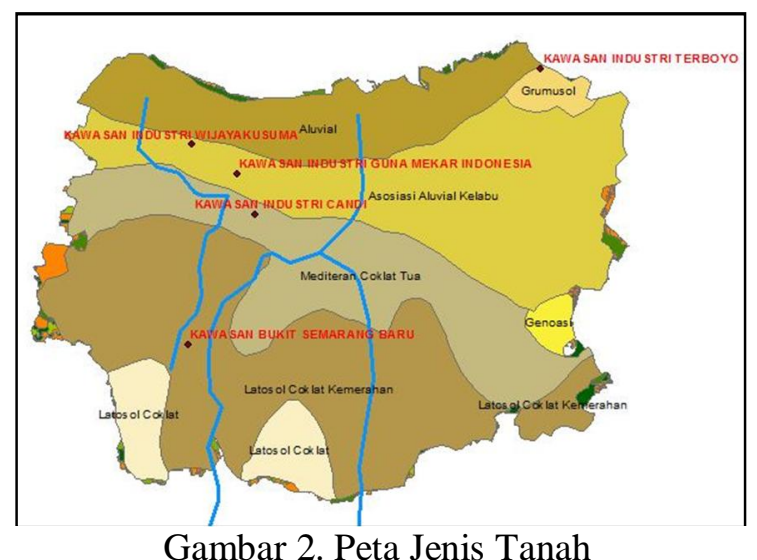

Gambar 2 adalah peta digital untuk data area jenis tanah yang kemudian dilakukan import ke database dan tersimpan dalam bentuk koordinat yang selanjutnya dilakukan query spatial untuk mengetahui lokasi industri berada pada area dengan jenis tanah apa. Masingmasing warna menunjukan jenis tanah yang berbeda untuk cakupan area yang berbeda pula. 


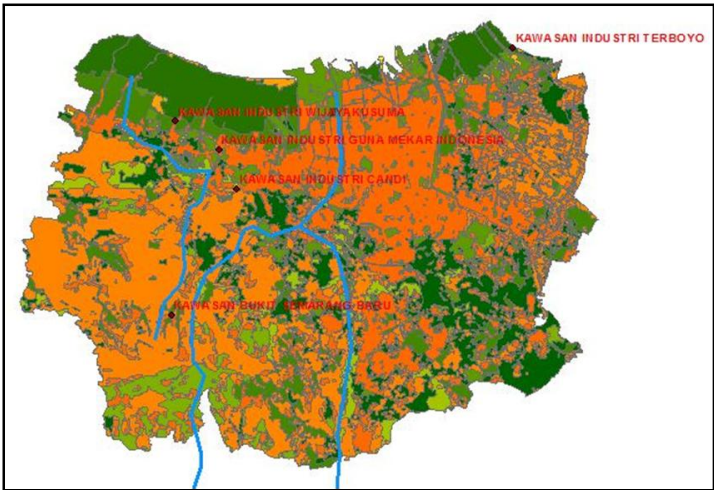

Gambar 3. Peta Jenis Lahan

Gambar 3 diatas adalah visualisasi peta digital untuk data jenis penggunaan lahan. Masing-masing warna menunjukan jenis lahan yang berbeda untuk cakupan area yang berbeda pula. Data peta yang sama juga digunakan untuk mencari jarak terdekat dengan area lahan untuk peruntukan pemukiman. Selain untuk mencari jenis lahan pada lokasi industri, juga diperoleh data jarak titik lokasi industri dengan areal jenis lahan pemukiman.

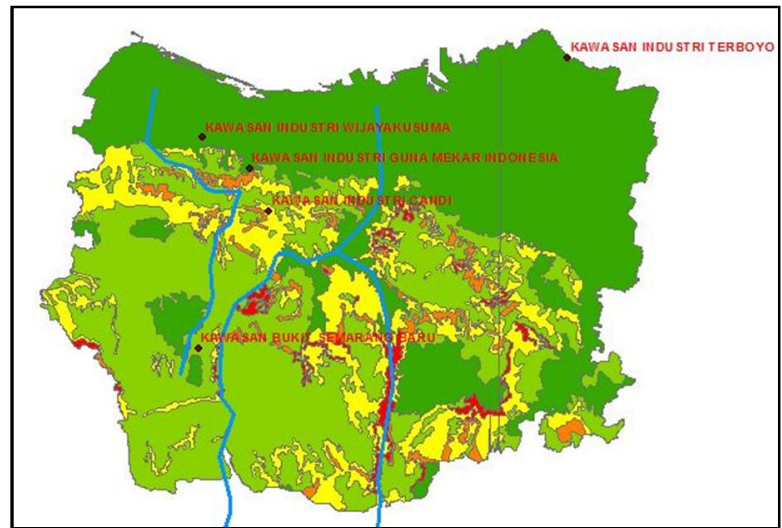

Gambar 4. Peta Kemiringan Lahan

Gambar 4 diatas ini adalah visualisasi peta digital untuk kemiringan lahan. Masingmasing warna menunjukan tingkat kemiringan atau kelerengan lahan yang berbeda untuk cakupan area yang berbeda pula.

Langkah pertama pada MOORA adalah menormalisasi matrik decision making dan bobot. Decision making matrix dinormalisasi menggunakan persamaan 2 untuk memperoleh nilai kriteria dengan rentang 0 sampai 1. Nilai bobot juga dilakukan normalisasi sehingga total seluruh nilai bobot adalah 1 yang ditunjukan pada tabel 2 dibawah ini.

Tabel 2. Bobot Kriteria

\begin{tabular}{|l|c|c|}
\hline Kriteria & Bobot & Normalisasi \\
\hline Kota & 5 & 0.21 \\
\hline Lahan & 3 & 0.13 \\
\hline Lereng & 2 & 0.08 \\
\hline Tanah & 2 & 0.08 \\
\hline Sungai & 3 & 0.13 \\
\hline Jalan & 5 & 0.21 \\
\hline Permukiman & 4 & 0.17 \\
\hline
\end{tabular}

Pinem, et, al [Sistem Pendukung Keputusan Penentuan Lokasi Industri Berbasis Spasial Menggunakan Metode MOORA] 
Matrik keputusan normalisasi terbobot selanjtunya digunakan untuk mencari nilai maximax dan minmax menggunakan persamaan 5 dan menghasilkan nilai Yi. Hasil nilai maximax dan minmax ditunjukan pada tabel 3

Tabel 3. Maximax dan Minimax

\begin{tabular}{|c|c|c|c|}
\hline Alternatif & Maksimum & Minimum & Yi (Max-Min) \\
\hline A1 & 0.05 & 0.38 & -0.336 \\
\hline A2 & 0.02 & 0.11 & -0.089 \\
\hline A3 & 0.13 & 0.21 & -0.074 \\
\hline A4 & 0.13 & 0.23 & -0.091 \\
\hline A5 & 0.02 & 0.14 & -0.126 \\
\hline
\end{tabular}

Nilai $Y i$ yang ditunjukan pada tabel 3 merupakan nilai akhir metode MOORA untuk digunakan sebagai acuan dalam perangkingan alternatif. Hasil metode MOORA menunjukan alternatif A3 menjadi alternatif terbaik dengan nilai terbesar. Nilai $Y i$ yang dihasilkan memiliki nilai minus dikarenakan jumlah kriteria dengan kategori cost lebih banyak daripada kategori benefit. Nilai terbesar berdasarkan nilai minus terkecil.

\section{HASIL DAN PEMBAHASAN}

Setelah dilakukan perhitungan akhir, diperoleh hasil sebagai berikut:

\begin{tabular}{|l|r|r|r|r|}
\hline f ALT & f & MAXIMAX & f MINMAX & | YI \\
\hline $1 \mathrm{~A} 1$ & 0.06 & 0.383 & -0.323 \\
\hline $2 \mathrm{~A} 2$ & 0.082 & 0.109 & -0.027 \\
\hline $3 \mathrm{~A} 3$ & 0.166 & 0.207 & -0.041 \\
\hline $4 \mathrm{~A} 4$ & 0.269 & 0.231 & 0.038 \\
\hline $5 \mathrm{~A} 5$ & 0.095 & 0.146 & -0.051 \\
\hline
\end{tabular}

Gambar 5. Hasil Nilai $Y i$

Gambar 5 merupakan hasil perhitungan $Y i$ yang diterapkan didalam database dengan melakukan join antar view dan materialized view. Dari output query menunjukan alternatif 4 memiliki nilai $Y i$ terbesar sehingga menjadi alternatif terbaik dari total lima alternatif yang tersedia.

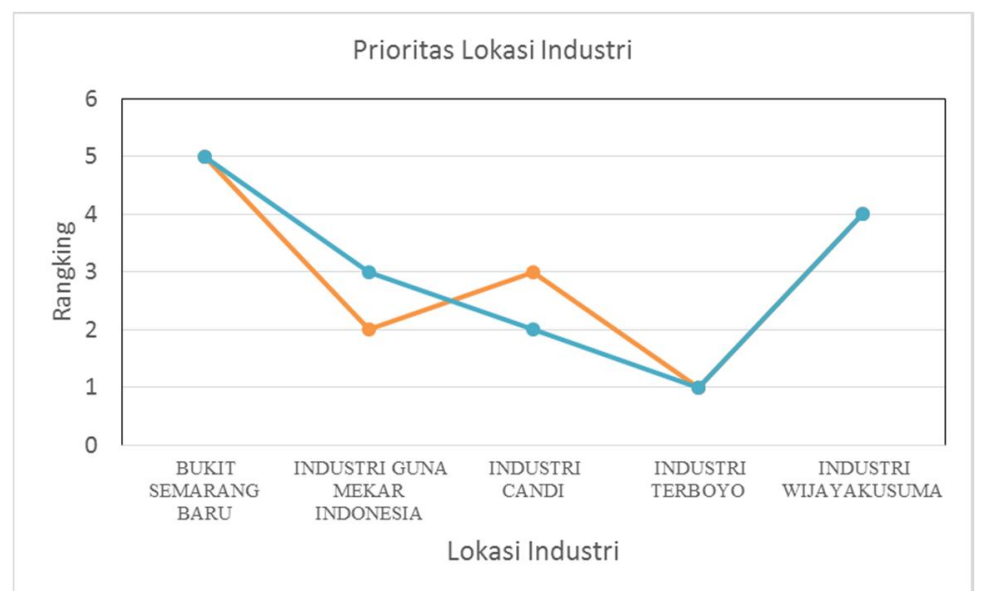

Gambar 6. Ploting Rangking MOORA dengan Data Sekunder 
Gambar 6 merupakan hasil validasi dengan Spearman Rank dengan membandingkan output metode MOORA dengan data sekunder prioritas (DPMPTSP). Nilai korelasi yang dihasilkan adalah 0.9 karena rangking dari output metode MOORA hampir sama dengan prioritas dari data sekunder DPMPTSP. Hal ini ditunjukan pada alternatif 2 dan 3 yang berbeda rangking. Nilai korelasi 0,9 menunjukan metode MOORA dapat dikatakan sesuai dengan kenyataan dalam penentuan prioritas lokasi industri.

Dalam proses validasi, penelitian ini menggunakan data sekunder dari Dinas Penanaman Modal dan Pelayanan Terpadu Satu Pintu (DPMPTSP) Kota Semarang data tahun 2017 tentang informasi kawasan industri di Kota Semarang terkait jumlah perusahaan, luas area dan prioritas. Proses validasi menggunakan data DPMPTSP Kota Semarang sebagai data real untuk selanjutnya dicari nilai korelasi dengan hasil metode MOORA. Berikut hasil validasi dengan menghitung nilai korelasi berdasarkan rangking yang dihasilkan metode MOORA dengan tabel data sekunder prioritas kawasan dari DPMPTSP Kota Semarang.

\section{KESIMPULAN}

Kesimpulan yang dapat ditarik dari penelitian ini adalah terbentuknya sistem pendukung keputusan dengan metode MOORA dengan menggunakan data berbasis spasial sebagai nilai kriteria untuk masing-masing alternatif. Melalui hasil pengujian perhitungan manual dengan output sistem memiliki nilai MSE sebesar 0,0000054. Sedangkan nilai validasi menggunakan korelasi Spearman Rank sebesar 0,9. Berdasarkan hasil pengujian dan validasi menunjukan bahwa metode MOORA dapat menentukan lokasi industri menggunakan data berbasis spasial dengan nilai korelasi yang mendekati nilai 1.

\section{SARAN}

Saran dari penelitian ini adalah lokasi kawasan industri berupa data spasial area bukan bertipe point, sehingga dapat dicari juga luas area tersebut. Selain itu perlu ditambahkan kriteria dengan dukungan data yang lengkap, seperti jaringan listrik dan komunikasi. Penggunaan bobot juga disarankan diperoleh dari lebih dari satu pengambil keputusan.

\section{UCAPAN TERIMA KASIH}

Terima kasih kepada Lembaga Penelitian dan Pengabdian kepada Masyarakat (LPPM) Universitas Semarang yang membantu dan memberikan dukungan terkait dengan penelitian yang dilakukan seperti bantuan fasilitas penelitian.

\section{DAFTAR PUSTAKA}

[1] R. K. Mavi, M. Goh, and N. Zarbakhshnia, 2017, "Sustainable Third-Party Reverse Logistic Provider Selection With Fuzzy SWARA and Fuzzy MOORA In Plastic Industry," The International Journal of Advanced Manufacturing Technology, Vol. 91, No. 5-8, pp. 2401-2418, Jul, doi: 10.1007/s00170-016-9880-x.

[2] Z. A. Siddiqui and K. Tyagi, 2016, "Application of fuzzy-MOORA method: Ranking of Components for Reliability Estimation of Component-Based Software Systems," Decision Science Letters, pp. 169-188, doi: 10.5267/j.dsl.2015.6.005.

Pinem, et, al [Sistem Pendukung Keputusan Penentuan Lokasi Industri Berbasis Spasial Menggunakan Metode MOORA] 
[3] H. Indriyawati, S. R. Cholil, and V. G. Utomo, 2018, "Penentuan Prediksi Stok Mobil Dengan Pendekatan Kepuasan Pelanggan Menggunakan Metode MOORA,” Vol. 11, No. 2, p. 10.

[4] A. Sarkar, S. C. Panja, D. Das, and B. Sarkar, 2015, "Developing an Efficient Decision Support System For Non-Traditional Machine Selection: An Application of MOORA and MOOSRA," Production \& Manufacturing Research, Vol. 3, No. 1, pp. 324-342, Jan. doi: 10.1080/21693277.2014.895688.

[5] A. Arabsheybani, M. M. Paydar, and A. S. Safaei, 2018, “An Integrated Fuzzy MOORA Method and FMEA Technique for Sustainable Supplier Selection Considering Quantity Discounts and Supplier's Risk," Journal of Cleaner Production, Vol. 190, pp. 577-591, Jul. 2018, doi: 10.1016/j.jclepro.04.167.

[6] C. R. Matawale, S. Datta, and S. S. Mahapatra, 2016, "Supplier Selection In Agile Supply Chain: Application Potential of FMLMCDM Approach in Comparison with Fuzzy-TOPSIS and FuzzyMOORA," Benchmarking: An International Journal, Vol. 23, No. 7, pp. 2027-2060, Oct, doi: 10.1108/BIJ-07-2015-0067.

[7] P. Karande and S. Chakraborty, 2012, "Application of Multi-Objective Optimization on The Basis of Ratio Analysis (MOORA) Method for Materials Selection," Materials \& Design, Vol. 37, pp. 317-324, May 2012, doi: 10.1016/j.matdes.01.013.

[8] J. D. Patel and K. D. Maniya, 2015, "Application of AHP/MOORA Method to Select Wire Cut Electrical Discharge Machining Process Parameter to Cut EN31 Alloys Steel with Brasswire," Materials Today: Proceedings, vol. 2, no. 4-5, pp. 2496-2503, doi: 10.1016/j.matpr.2015.07.193.

[9] L. Pérez-Domínguez, L. A. Rodríguez-Picón, A. Alvarado-Iniesta, D. Luviano Cruz, and Z. Xu, 2018, "MOORA Under Pythagorean Fuzzy Set for Multiple Criteria Decision Making," Complexity, Vol. 2018, pp. 1-10, doi: 10.1155/2018/2602376.

[10] J. Afriany, L. R. S. B. Sinurat, I. Julianty, and E. L. Nainggolan, 2018, "Penerapan MOORA Untuk Mendukung Efektifitas Keputusan Manajemen Dalam Penentuan Lokasi SPBU,” Vol. 5, No. 2, p. 6.

[11] H. Lu, M. L. Yiu, and X. Xie, 2018, "Querying Spatial Data by Dominators In Neighborhood," Information Systems, Vol. 77, pp. 71-85, Sep, doi: 10.1016/j.is.2018.06.001.

[12] W. S. Nugraha, S. Subiyanto, and A. P. Wijaya, 2015, "Penentuan Lokasi Potensial Untuk Pengembangan Kawasan Industri Menggunakan Sistem Informasi Geografis di Kabupaten Boyolali," Jurnal Geodesi Undip, Vol. 4, p. 9.

[13] K. Ulfa Fathul and S. Subiyanto, 2017, "Penentuan Kawasan Peruntukan Industri Menggunakan Analytical Hierarchy Process (Ahp) dan Sistem Informasi Geografis (Studi Kasus: Kabupaten Sragen)," Jurnal Geodesi Undip, Vol. 6, p. 9. 